\title{
Structure-activity relationships regarding the antioxidant effects of the flavonoids on human erythrocytes
}

\author{
Yousif Y. Bilto ${ }^{1^{*}}$, Sanaa Suboh ${ }^{1}$, Talal Aburjai ${ }^{2}$, Shtywy Abdalla ${ }^{1}$ \\ ${ }^{1}$ Department of Biological Sciences, University of Jordan, Amman, Jordan; * Corresponding Author: bilto@ju.edu.jo \\ ${ }^{2}$ Faculty of Pharmacy, University of Jordan, Amman, Jordan
}

Received 23 July 2012; revised 25 August 2012; accepted 10 September 2012

\begin{abstract}
The effects of eleven flavonoids on lipid peroxidation, protein degradation, deformability and osmotic fragility of human erythrocytes exposed in vitro to $10 \mathrm{mM} \mathrm{H} \mathrm{O}_{2}$ for $60 \mathrm{~min}$ at $37^{\circ} \mathrm{C}$ have been studied. The following flavonoids; quercetin, rutin and morin significantly protected erythrocytes against lipid peroxidation caused by $\mathrm{H}_{2} \mathrm{O}_{2}$. This inhibition of lipid peroxidation could be explained by the presence of at least two hydroxyl groups in ring $B$ of the flavonoid structure, regardless of their positions. However, the flavonoids; quercetin, 3,5,7-trihydroxy-4'-methoxy flavone-7-rutinoside and 3-hydroxy flavone significantly protected erythrocytes against protein degradation. This inhibition could also be explained by the presence of a hydroxyl group at $\mathrm{C}-3$ in ring $\mathrm{C}$ of the flavonoid structure. Quercetin and 3,5,7-trihydroxy-4'-methoxy flavone-7-rutinoside significantly protected erythrocytes against loss of deformability and increased osmotic fragility, indicating that the loss of erythrocyte deformability and the increase in osmotic fragility of erythrocytes exposed to $\mathrm{H}_{2} \mathrm{O}_{2}$ are related to protein degradation rather than to lipid peroxidation. The other flavonoids (chrysin, 2-carboxy ethyl dihydroxy flavone, apigenin, cirsimaritin, $\alpha$-naphto flavone and flavanone) failed to protect erythrocytes against the observed oxidative damages. The results demonstrate the importance of the chemical groups substituted on the basic skeleton of the flavonoids in dictating the type of antioxidant activity, and also demonstrate the hemorheological potentials of flavonoids that have particular protein-antioxidant activities.
\end{abstract}

Keywords: Erythrocyte Deformability; Lipid
Peroxidation; Protein Degradation; Oxidative Stress; $\mathrm{H}_{2} \mathrm{O}_{2}$; Flavonoids; Structure-Activity Relationships

\section{INTRODUCTION}

Erythrocytes are susceptible to oxidative damage as a result of the high polyunsaturated fatty acid content of their membranes and the high cellular concentrations of oxygen and haemoglobin [1]. In healthy erythrocytes, significant oxidative damage is prevented by a very efficient antioxidant system, consisting of a number of antioxidant compounds and enzymes [2]. However, when free radicals overwhelm the capacity of antioxidant system in the erythrocyte, oxidative damages may occur endangering the integrity of the erythrocytes $[3,4]$. In vitro exposure of erythrocytes to oxygen radical generating systems (such as $\mathrm{H}_{2} \mathrm{O}_{2}$, ascorbate $/ \mathrm{Fe}^{3+}$, cumene hydroperoxide, tert-butyl hydroperoxide, etc.) was shown to induce lipid peroxidation, protein degradation, loss of deformability, an increase in osmotic fragility, membrane lipid bilayer perturbation, inhibition of enzymes and hemolysis [5-12]. However, Free radical reactions occur in the human body and food systems. Free radicals, in the form of reactive oxygen and nitrogen species, are an integral part of normal physiology. An over-production of these reactive species can occur in the human body, due to oxidative stress brought about by the imbalance of the body antioxidant defense system and free radical accumulation. These reactive species can react with biomolecules, causing cellular injury and death. This may lead to the development of chronic diseases such as those involve the cardio- and cerebro-vascular systems and cancers. The consumption of fruits and vegetables containing antioxidants has been found to offer protection against these diseases. Dietary antioxidants can augment cellular defenses and help to prevent oxidative damage to cellular components [13]. Plants are rich in phenolic compounds and flavonoids which have been reported to exert multiple biological effects, such as antioxidant ac- 
tivities, free radical scavenging abilities, anti-inflammatory and anti-carcinogenic [14]. Epidemiological and in vitro studies on medicinal plants and vegetables strongly support the idea that plant constituents with antioxidant activity are capable of exerting protective effects against oxidative stress in biological systems [15-17]. Crude extracts of herbs and other plant materials are rich in phenols and flavonoids and several studies reported a positive linear correlation between the total phenolic compounds and the antioxidant activities of aqueous and methanolic extracts of different plant species $[18,19]$. The antioxidant activity of phenols and flavonoids is mainly due to their redox properties, which allow them to act as reducing agents, electron/hydrogen donators, and singlet oxygen quenchers. In addition, they have a metal chelating potential [20]. The unique chemical structures of phenolic compounds that are characterized by an aromatic ring possessing one or more hydroxyl substituents are predictive of their antioxidant potential in terms of radical scavenging, hydrogen- or electron-donating and metal-chelating capacities [21]. The flavonoids contain a C6-C3-C6 flavon skelton (Table 1) in which the three-carbon bridge is cyclismed with oxygen
[22]. The antioxidant activity of phenolic compounds including flavonoids is related to the acid moiety and the number and relative positions of hydroxyl groups on the aromatic ring structure $[20,23]$.

An earlier study from our laboratory indicated that the antioxidant effects of medicinal plants on human erythrocytes could be varied from being either anti-lipid peroxidant, anti-protein degradant or having both activities [24]. This variation in the property of antioxidant activity could be due to the structural variation of the antioxidant compounds involved. The present study therefore aimed to screen selected flavonoids with known chemical structures (Table 1), for their protective effects against lipid peroxidation, protein degradation, deformability loss and increased osmotic fragility of human erythrocytes exposed to $\mathrm{H}_{2} \mathrm{O}_{2}$. This study also aimed to draw conclusions based on the structure-activity relationships regarding the antioxidant properties of the flavonoids.

\section{MATERIALS AND METHODS}

\subsection{Flavonoids}

Stock solutions of the flavonoids (All Aldrich Chemi-

Table 1. List of studied flavonoids with their chemical structures.

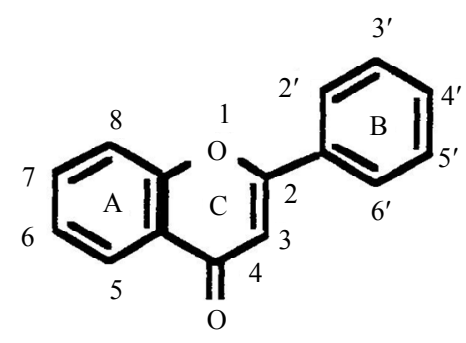

\begin{tabular}{|c|c|c|c|c|c|c|}
\hline \multirow{2}{*}{ Flavonoid } & \multicolumn{6}{|c|}{ Substitutions } \\
\hline & 3 & 5 & 7 & 2 & 3 ' & 4 ' \\
\hline Quercetin & $\mathrm{OH}$ & $\mathrm{OH}$ & $\mathrm{OH}$ & - & $\mathrm{OH}$ & $\mathrm{OH}$ \\
\hline Rutin & OR1 & $\mathrm{OH}$ & $\mathrm{OH}$ & - & $\mathrm{OH}$ & $\mathrm{OH}$ \\
\hline Morin & $\mathrm{OH}$ & $\mathrm{OH}$ & $\mathrm{OH}$ & $\mathrm{OH}$ & - & $\mathrm{OH}$ \\
\hline 3,5,7-trihydroxy-4'-methoxy flavone-7-rutinoside & $\mathrm{OH}$ & $\mathrm{OH}$ & OR1 & - & - & $\mathrm{OMe}$ \\
\hline 3-hydroxy flavone & $\mathrm{OH}$ & - & - & - & - & - \\
\hline Chrysin & - & $\mathrm{OH}$ & $\mathrm{OH}$ & - & - & - \\
\hline 2-carboxy ethyl dihydroxy flavone & - & $\mathrm{OH}$ & $\mathrm{OH}$ & - & $\mathrm{OMe}$ & - \\
\hline Apigenin & - & $\mathrm{OH}$ & $\mathrm{OH}$ & - & - & $\mathrm{OH}$ \\
\hline Cirsimaritin & - & $\mathrm{OH}$ & $\mathrm{OMe}$ & - & $\mathrm{OH}$ & - \\
\hline$\alpha$-naphtho flavone & - & - & - & - & - & - \\
\hline Flavanone & $\mathrm{H}$ & _- & _ & - & - & - \\
\hline
\end{tabular}

$\mathrm{R} 1$ = rhamnose-glucose. 
cal Company, Milwaukee, USA) were prepared by dissolving the powder form of the flavonoid in a few drops of $0.1 \mathrm{~N} \mathrm{NaOH}$ and then making up the required volume with normal saline. These stock solutions $(1.2 \mathrm{mg} / \mathrm{ml})$ were stored in the refrigerator at $4^{\circ} \mathrm{C}$ until use. The flavonoids used and their chemical structures are shown in Table 1.

\subsection{Exposure of Erythrocytes to $\mathrm{H}_{2} \mathrm{O}_{2}$ with and without Flavonoids}

Washed erythrocyte suspensions were prepared by centrifugation of heparinized whole blood from adult volunteers, who were told and explained to the objectives of this study and venous blood drawn after taking their consent, to remove the buffy coat layer and then washing the packed cells three times with cold phosphate buffered saline (PBS) as described by Dacie and Lewis [25]. Washed erythrocyte suspensions were pre-incubated with $2 \mathrm{mM}$ sodium azide for $60 \mathrm{~min}$ at $37^{\circ} \mathrm{C}$ in a shaking water bath to inhibit catalase. Next, equal volumes of cell suspension and $20 \mathrm{mM} \mathrm{H} \mathrm{H}_{2}$ were mixed and incubated for a further $60 \mathrm{~min}$ at $37^{\circ} \mathrm{C}$. Controls contained PBS instead of $\mathrm{H}_{2} \mathrm{O}_{2}$. Following the incubation period, the suspensions were mixed and used for MDA and alanine determinations as well as for deformability and fragility studies [12]. A given flavonoid at a final concentration of $90 \mu \mathrm{g} / \mathrm{ml}$ (i.e. $75 \mu \mathrm{l} / \mathrm{ml}$ ) was added to erythrocyte suspensions at $30 \mathrm{~min}$ of the pre-incubation period with sodium azide.

\subsection{Malonyldialdehyde (MDA) Determination}

Erythrocyte MDA was determined as a measure of lipid peroxidation according to Stocks and Dormandy's method [26] as modified by Srour et al. [27]. The principle of this method depends on extraction of MDA from erythrocyte suspension by trichloroacetic acid (TCA) solution. MDA in the TCA extract is then reacted with thiobarbituric acid (TBA) giving a pink colored complex (absorption max $532 \mathrm{~nm}$ ). To $2.0 \mathrm{ml}$ erythrocyte suspension (2.5\% in PBS), $1.0 \mathrm{ml}$ of TCA-arsenate (TCA 28\%, arsenate $0.1 \mathrm{M}$ ) was added and mixed. This mixture was centrifuged for $15 \mathrm{~min}$ at $1050 \mathrm{~g}(6000 \mathrm{rpm})$. An aliquot $(2.0 \mathrm{ml})$ of the supernatant was mixed with $0.5 \mathrm{ml}$ of TBA solution $(1 \%$ in $0.05 \mathrm{M} \mathrm{NaOH})$. This mixture was placed in a boiling water bath for exactly $15 \mathrm{~min}$, then immediately cooled under tap water. The absorption of the reaction mixture was read at $532 \mathrm{~nm}$ against reagent blank. For experiments that involved sodium azide, the absorbance was also read at $600 \mathrm{~nm}$, and the difference between $532 \mathrm{~nm}$ and $600 \mathrm{~nm}$ was used as the basis for calculation of MDA concentration. For preparation of the standard curve, standard MDA (1,1,3,3,-tetraethoxypro- pane) dissolved in distilled water $(4-20 \mathrm{nmol} / \mathrm{ml})$ was assayed as above. All MDA concentrations were expressed in $\mathrm{nmol} / \mathrm{g} \mathrm{Hb}$. All MDA concentrations were expressed in $\mathrm{nmol} / \mathrm{g} \mathrm{Hb}$. The $\mathrm{Hb}$ was measured by the cyanmethemoglobin method as described by Dacie and Lewis [25].

\subsection{Alanine Determination}

Alanine is not synthesized de novo in erythrocytes, so net production of alanine can only occur via protein degradation. Erythrocyte alanine concentration was determined as a measure of protein degradation was determined by the alanine dehydrogenase (ADase) method at alkaline $\mathrm{pH}$ as described by Davies and Goldberg method [28] and modified by Srour et al. [12]. To $3.0 \mathrm{ml}$ of erythrocyte suspensions, was added $1.0 \mathrm{ml}$ of cold $1.6 \mathrm{M}$ perchloric acid. After vortexing and $10 \mathrm{~min}$ on ice, the suspensions were centrifuged at $500 \mathrm{~g}$ for $10 \mathrm{~min}$. Then $1.0 \mathrm{ml}$ aliquots of the supernatants were taken to $\mathrm{pH} 9.0$ with $0.2 \mathrm{ml}$ of $2.0 \mathrm{M} \mathrm{KOH}$ and buffered by the addition of $0.8 \mathrm{ml}$ of $0.5 \mathrm{M}$ Tris-HC1 (pH 9.0). After 1 - $2 \mathrm{hrs}$ on ice, during which the perchlorate precipitated, the alanine content of each sample supernatant was measured. To 0.5 $\mathrm{ml}$ aliquot of each supernatant, the following reagents were added; $0.5 \mathrm{ml}$ of $0.8 \mathrm{M}$ Tris-HC1 (pH 9.0) buffer containing $0.04 \mathrm{M}$ EDTA, $0.5 \mathrm{ml}$ of $6.6 \%$ hydrazine hydrate solution $(\mathrm{pH} 9.0), 0.1 \mathrm{ml}$ of $20 \mathrm{mg} / \mathrm{ml} \mathrm{NAD}{ }^{+}$and $0.1 \mathrm{ml}$ of $6 \mathrm{IU} / \mathrm{ml}$ alanine dehydrogenase. After incubation for $60 \mathrm{~min}$ at $37^{\circ} \mathrm{C}$, the alanine content was determined spectrophotometrically at $340 \mathrm{~nm}$ by the reduction of $\mathrm{NAD}^{+}$to NADH. Standard alanine solutions (5-25 $\mathrm{nmol} / \mathrm{ml}$ ) were assayed along the erythrocyte suspensions to construct a standard curve. All alanine concentrations were expressed in $\mathrm{nmol} / \mathrm{g} \mathrm{Hb}$. The $\mathrm{Hb}$ was measured by the cyanmethemoglobin method as described by Dacie and Lewis [25].

\subsection{Deformability Studies}

Leukocyte-depleted and platelet-depleted erythrocyte suspensions were prepared by pre-filtration of heparinnized whole blood from adult volunteers through Imugard IG500 cotton wool (Termo corporation, Tokyo, Japan) as described by Bilto et al. [29]. The cotton wool filtered erythrocytes were resuspended in PBS at a hematocrit of $7 \%$ and then exposed to $\mathrm{H}_{2} \mathrm{O}_{2}$ with and without flavonoids as described above. Erythrocyte deformability was measured by filtration of erythrocyte suspension through $5 \mu \mathrm{m}$ pore diameter polycarbonate membranes (Nuclepore corporation, Pleasanton, USA) using a temperature controlled Hemorheometre MK1 [30] at $37^{\circ} \mathrm{C}$. A small batch of 12 membranes was used and reused after cleaning by ultrasonication in aqueous sodium dodecylsulfate $(1 \%, \mathrm{w} / \mathrm{v})$ for 10 seconds [31]. Re- 
sults were expressed as an index of filtration (IF) of the flow time for the erythrocyte suspension relative to buffer and corrected for hematocrit [29]. An increase in IF indicates loss of deformability.

\subsection{Osmotic Fragility Measurements}

Aliquots $(0.2 \mathrm{ml})$ of erythrocyte suspensions $(2.5 \%$ hematocrit) incubated with $\mathrm{H}_{2} \mathrm{O}_{2}$ in the presence and absence of flavonoids at a final concentration of 90 $\mu \mathrm{g} / \mathrm{ml}$ (i.e. $75 \mu \mathrm{l} / \mathrm{ml}$ ) were added to $1.8 \mathrm{ml}$ of buffered saline solutions of decreasing concentrations, $\mathrm{pH} 7.4$, $(\mathrm{NaCl}$ range of $9.0-1.0 \mathrm{~g} / \mathrm{l})$. The suspensions were mixed and then allowed to stand for $30 \mathrm{~min}$ at room temperature, mixed again and then centrifuged for $5 \mathrm{~min}$ at $1200 \mathrm{rpm}$. The supernatants were removed and the amount of lysis was determined spectrophotometrically at $540 \mathrm{~nm}$. The percentage of hemolysis was calculated from the ratios of the absorbances [25].

\subsection{Statistical Analysis}

The results presented are means \pm SD of 5 separate experiments for each test with duplicate tubes. Statistical significance was determined using one-way analysis of variance followed by Student's $t$-test for paired samples. Differences were considered significant when $\mathrm{p}<$ 0.05 .

\section{RESULTS}

Incubation of erythrocytes with $\mathrm{H}_{2} \mathrm{O}_{2}$ for $60 \mathrm{~min}$ at $37^{\circ} \mathrm{C}$ caused a significant increase in intracellular MDA (i.e. an increase in lipid peroxidation) from $20.0 \pm 3.7$ $\mathrm{nmol} / \mathrm{g} \mathrm{Hb}$ without $\mathrm{H}_{2} \mathrm{O}_{2}$ to $402.0 \pm 56.7 \mathrm{nmol} / \mathrm{g} \mathrm{Hb}$ with $\mathrm{H}_{2} \mathrm{O}_{2}$ (Table 2). When erythrocytes were pre-incubated with $90 \mathrm{mg} / \mathrm{ml}$ of tested flavonoids, only quercetin, rutin and morin caused a significant inhibition of MDA production (Table 2).

Incubation of erythrocytes with $\mathrm{H}_{2} \mathrm{O}_{2}$ for $60 \mathrm{~min}$ at $37^{\circ} \mathrm{C}$ also caused a significant increase in intracellular alanine (i.e. an increase in protein degradation) from 519 $\pm 108 \mathrm{nmol} / \mathrm{g} \mathrm{Hb}$ without $\mathrm{H}_{2} \mathrm{O}_{2}$ to $3504 \pm 280 \mathrm{nmol} / \mathrm{g} \mathrm{Hb}$ with $\mathrm{H}_{2} \mathrm{O}_{2}$ (Table 2). When erythrocytes were pre-incubated with $90 \mathrm{mg} / \mathrm{ml}$ of tested flavonoids, only quercetin, 3,5,7-trihydroxy-4'-methoxy flavone-7-rutininoside and 3-hydroxy flavone caused a significant inhibition of alanine production (Table 2).

Incubation of erythrocytes with $\mathrm{H}_{2} \mathrm{O}_{2}$ for 60 min at $37^{\circ} \mathrm{C}$ also caused a significant increase in IF (i.e. loss of deformability) from $11.9 \pm 2.4$ without $\mathrm{H}_{2} \mathrm{O}_{2}$ to $116.4 \pm$ 10.5 with $\mathrm{H}_{2} \mathrm{O}_{2}$ (Table 2). Pre-incubation of erythrocytes with $90 \mathrm{mg} / \mathrm{ml}$ of quercetin or 3,5,7-trihydroxy-4'methoxy flavone-7-rutinoside prevented significantly the deformability loss of erythrocytes exposed to $\mathrm{H}_{2} \mathrm{O}_{2}$, whereas pre-incubation of erythrocytes with other flavonoids such as rutin, morin, chrysin, 2-carboxy ethyl

Table 2. Alanine and MDA concentrations, and IF of normal erythrocytes when incubated at $37^{\circ} \mathrm{C}$ for 60 min with or without $10 \mathrm{mM}$ $\mathrm{H}_{2} \mathrm{O}_{2}$ or with $\mathrm{H}_{2} \mathrm{O}_{2}$ plus $90 \mu \mathrm{g} / \mathrm{ml}$ tested flavonoids. Values are presented as a mean \pm S.D. of 5 experiments with duplicate tubes.

\begin{tabular}{|c|c|c|c|c|c|c|c|}
\hline \multirow[b]{2}{*}{ Flavonoid } & \multirow[b]{2}{*}{ Conc. $(\mu \mathrm{g} / \mathrm{ml})$} & \multicolumn{2}{|c|}{ Alanine (nmol/g Hb) } & \multicolumn{2}{|c|}{ MDA (nmol/g Hb) } & \multicolumn{2}{|c|}{ IF } \\
\hline & & without $\mathrm{H}_{2} \mathrm{O}_{2}$ & with $\mathrm{H}_{2} \mathbf{O}_{2}$ & without $\mathrm{H}_{2} \mathbf{O}_{2}$ & with $\mathrm{H}_{2} \mathrm{O}_{2}$ & without $\mathrm{H}_{2} \mathbf{O}_{2}$ & with $\mathrm{H}_{2} \mathrm{O}_{2}$ \\
\hline Control & $\mathbf{0}$ & $519 \pm 108$ & $3504 \pm 280$ & $20.0 \pm 3.7$ & $402.0 \pm 56.7$ & $11.9 \pm 2.4$ & $116.4 \pm 10.5$ \\
\hline Quercetin & 90 & $501 \pm 80$ & $2479 \pm 199^{*}$ & $23.0 \pm 3.3$ & $195.9 \pm 39.5^{*}$ & $11.5 \pm 1.8$ & $70.5 \pm 8.6^{*}$ \\
\hline Rutin & 90 & $505 \pm 106$ & $3498 \pm 208$ & $21.0 \pm 5.4$ & $247.5 \pm 33.0^{*}$ & $11.1 \pm 1.3$ & $118.3 \pm 14.5$ \\
\hline Morin & 90 & $510 \pm 76$ & $3750 \pm 265$ & $23.0 \pm 7.0$ & $264.0 \pm 45.0^{*}$ & $12.0 \pm 2.1$ & $120.3 \pm 13.5$ \\
\hline $\begin{array}{l}\text { 3,5,7-trihydroxy-4'-methoxy } \\
\text { flavone-7-rutinoside }\end{array}$ & 90 & $586 \pm 87$ & $2950 \pm 161^{*}$ & $20.0 \pm 9.0$ & $377.7 \pm 46.0$ & $11.6 \pm 2.4$ & $86.5 \pm 12.4^{*}$ \\
\hline 3-hydroxy flavone & 90 & $586 \pm 45$ & $2860 \pm 202^{*}$ & $24.0 \pm 3.0$ & $406.0 \pm 48.0$ & - & - \\
\hline Chrysin & 90 & $530 \pm 45$ & $3621 \pm 295$ & $22.1 \pm 6.5$ & $393.0 \pm 44.1$ & $10.3 \pm 2.8$ & $110.9 \pm 15.5$ \\
\hline $\begin{array}{l}\text { 2-carboxy ethyl dihydroxy } \\
\text { flavone }\end{array}$ & 90 & $506 \pm 40$ & $3710 \pm 302$ & $19.5 \pm 6.0$ & $407.0 \pm 40.1$ & $10.5 \pm 2.6$ & $120.3 \pm 11.2$ \\
\hline Apigenin & 90 & $485 \pm 55$ & $3514 \pm 324$ & $24.0 \pm 6.0$ & $400.0 \pm 34.0$ & - & - \\
\hline Cirsimaritin & 90 & $564 \pm 32$ & $3500 \pm 234$ & $20.0 \pm 5.0$ & $398.0 \pm 35.0$ & - & - \\
\hline$\alpha$-naphtho flavone & 90 & $564 \pm 67$ & $3369 \pm 263$ & $20.0 \pm 4.0$ & $416.1 \pm 34$ & $11.6 \pm 2.9$ & $114.0 \pm 18.0$ \\
\hline Flavanone & 90 & $490 \pm 76$ & $3425 \pm 265$ & $21.1 \pm 5.4$ & $389.0 \pm 40.0$ & $10.3 \pm 2.5$ & $115.6 \pm 15.0$ \\
\hline
\end{tabular}

-: Not determined; *: $\mathrm{P}<0.05$, compared to control erythrocytes with $\mathrm{H}_{2} \mathrm{O}_{2}$ alone. 
dihydroxy flavone, $\alpha$-naphtho flavone and flavanone showed no effect on deformability loss caused by $\mathrm{H}_{2} \mathrm{O}_{2}$ (Table 2).

In an attempt to explain the observed effects of $\mathrm{H}_{2} \mathrm{O}_{2}$ and the tested flavonoids on erythrocyte deformability, the osmotic fragility of erythrocytes exposed to $\mathrm{H}_{2} \mathrm{O}_{2}$ and to tested flavonoids was studied. As shown in Figure 1, erythrocytes exposed to $\mathrm{H}_{2} \mathrm{O}_{2}$ showed increased osmotic fragility (as the osmotic curve shifted to the right position) when compared to control erythrocytes incubated in the absence of $\mathrm{H}_{2} \mathrm{O}_{2}$. However, pre-incubation of erythrocytes with rutin and $\alpha$-naphtho flavone which did not have any effect on either alanine production or erythrocyte deformability, showed no effect on the osmotic fragility of erythrocytes exposed to $\mathrm{H}_{2} \mathrm{O}_{2}$, since they didn't affect the position of the osmotic curve for these erythrocytes (Figure 1). In contrast, quercetin and 3,5,7-trihydroxy-4'-methoxy flavone-7-rutinoside which inhibited alanine production and prevented the deformability loss improved the fragility of erythrocytes exposed to $\mathrm{H}_{2} \mathrm{O}_{2}$, since they shifted the osmotic curve for these erythrocytes towards the left (Figure 1).

\section{DISCUSSION}

The present study evaluated the antioxidant properties of eleven flavonoids using human erythrocytes exposed to $10 \mathrm{mM} \mathrm{H}_{2} \mathrm{O}_{2}$ (Table 2). The results of lipid peroxidation (Table 2) showed that flavonoids with no or with one hydroxyl group in ring B (e.g., 3,5,7-trihydroxy-4'-methoxy flavone-7-rutinoside, 3-hydroxy flavone, chrysin, 2-carboxy ethyl dihydroxy flavone, $\alpha$ naphtho flavone and flavanone, cirsimaritin and apigenin) had no effects on MDA production. Whereas, quercetin and its 3-rutinoside (rutin), which both have ortho 3',4'-dihydroxy substitution in ring $\mathrm{B}$, inhibited significantly the MDA production in $\mathrm{H}_{2} \mathrm{O}_{2}$-treated erythrocytes (Table 2). This emphasizes the importance of the ortho 3',4'-dihydroxy substitution in ring B for the inhibition of lipid peroxidation. However, the hydroxyl groups at C-3 and C-5 do not seem to be important for this inhibition, as the C-3 hydroxyl group in rutin (which inhibited lipid peroxidation) is replaced by a disaccharide and the flavonoids which have C-5 hydroxyl groups did not inhibit lipid peroxidation. These results are consistent with

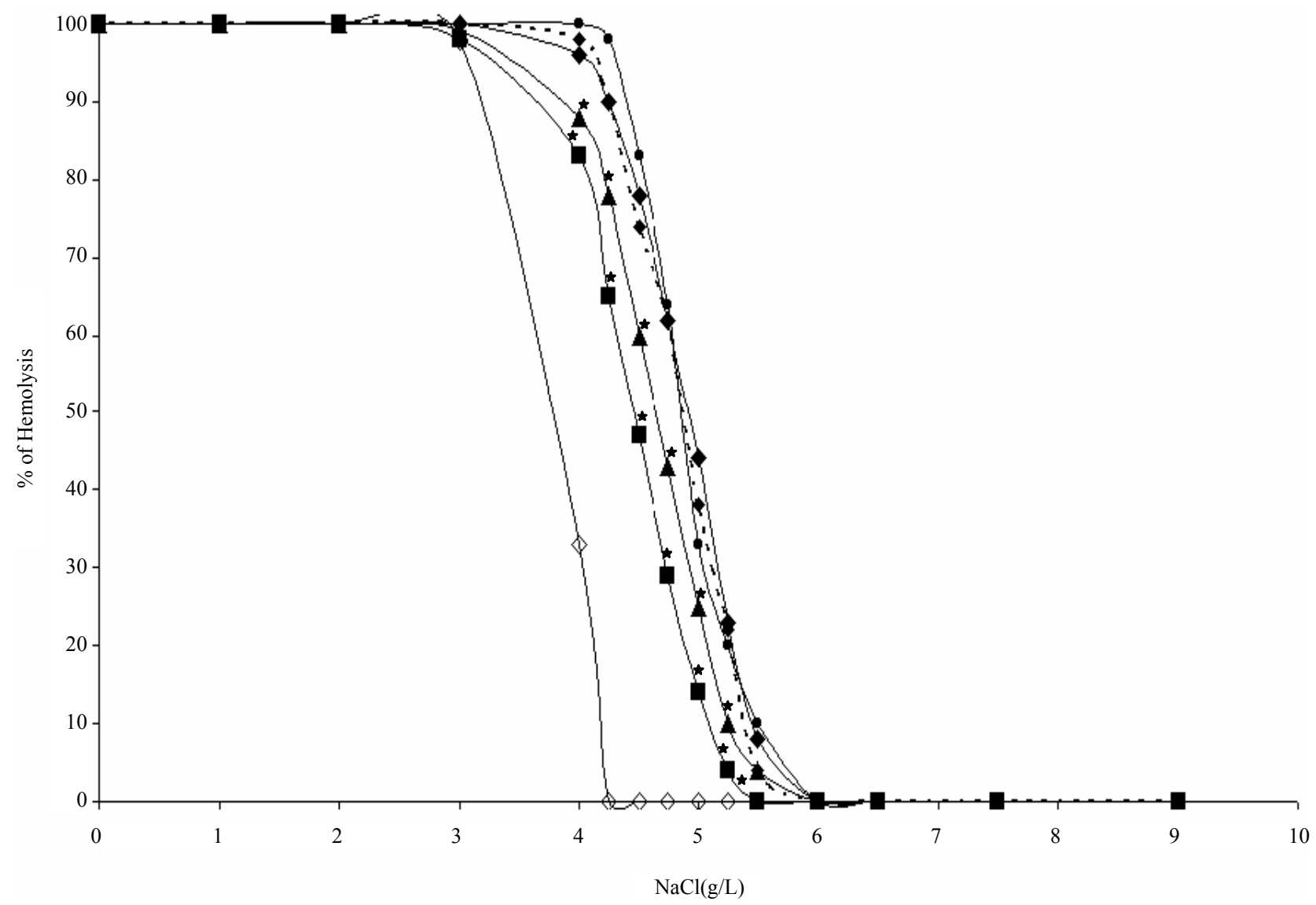

Figure 1. Osmotic fragility curves for heparinized erythrocytes incubated at $37^{\circ} \mathrm{C}$ for $30 \mathrm{~min}$ in the absence $(-\diamond)$ or in the presence of $10 \mathrm{mM} \mathrm{H}_{2} \mathrm{O}_{2}(-)$ ) or in the presence of $10 \mathrm{mM} \mathrm{H}_{2} \mathrm{O}_{2}$ plus $90 \mu \mathrm{g} / \mathrm{ml}$ quercetin $(\rightarrow)$ or $90 \mu \mathrm{g} / \mathrm{ml} \mathrm{3,5,7-trihydroxy} \mathrm{4'-methoxy} \mathrm{fla-}$ vone-7-rutinoside (- $)$ or $90 \mu \mathrm{g} / \mathrm{ml}$ rutin $(-+)$ or $90 \mu \mathrm{g} / \mathrm{ml} \alpha$-naphtho flavone $(-)$ ). Each point represents the mean of five experiments. ${ }^{*}: \mathrm{P}<0.05$ as compared with erythrocytes treated with $\mathrm{H}_{2} \mathrm{O}_{2}$ alone. 
those of other researchers [32] who found that quercetin protected $\mathrm{H}_{2} \mathrm{O}_{2}$ induced lipid peroxidation of erythrocytes, and with others [33] who found that quercetin and rutin protected low-density lipoproteins (LDL) against $\mathrm{Cu}^{2+}$ ion-dependent oxidation, and also with others [34] who found that flavonoids which possess only one hydroxyl group at C-4' on the B ring and which also lack the C-3 hydroxyl group (i.e. apigenin and chrysin) did not show a scavenging activity towards peroxynitrite, whereas, quercetin showed the most prominent scavenging activity of all the tested flavonoids. The precise mechanism by which the ortho 3',4'-dihydroxy groups protected lipids against peroxidation is uncertain, likely mechanisms could be their oxidation by the free radicals, thus scavenging the free radicals, and/or chelation of iron and thus reduction of free radical formation [33,35-40].

As lipid peroxidation was also inhibited by the flavonoid morin (Table 2), which has meta 2',4'-dihydroxy substitution in ring $B$, it seems that the number of hydroxyl groups located in ring B of the flavonoid could also be important for the inhibition of lipid peroxidation, with two hydroxyl groups being the minimum requirement, regardless of their positions. In support of this, it has been reported that the scavenging activity of flavonoids for hydroxyl radicals increases with the number of hydroxyl groups substituted in ring $\mathrm{B}$, and that the presence of hydroxyl group at C-3 or its glycosylation does not further increase the scavenging effect [37,41]. Consequently, it seems that oxidation of the meta 2',4'dihdroxy groups by free radicals could have been responsible for the anti-lipid-peroxidant activity of morin observed in the present study. The anti-lipid-peroxidant activities for quercetin, rutin and morin were also observed by Affany et al. [42], who also found no effect for the flavonoid flavone which supports further our results and the conclusion reached above.

Quercetin, 3,5,7-trihydroxy-4'-methoxy flavone-7-rutinoside and 3-hydroxy flavone significantly protected erythrocytes against protein degradation as compared with those treated with $\mathrm{H}_{2} \mathrm{O}_{2}$ alone (Table 2). In contrast, the flavonoids rutin, morin, chrysin, 2-carboxy ethyl dihydroxy flavone, apigenin, cirsimaritin, $\alpha$-naphtho flavone and flavanone were not able to stop this protein degradation (Table 2). This emphasizes the importance of the hydroxyl group at $\mathrm{C}-3$ in ring $\mathrm{C}$ for the inhibition of protein degradation, while other hydroxyl groups in $\mathrm{A}$ and $\mathrm{B}$ rings do not seem to be important for the observed inhibitory activity of protein degradation. The precise mechanism by which these flavonoids protected proteins against degradation is uncertain. However, Brown et al. [33] reported that the presence of a C-3 hydroxyl group in the flavonoid structure enhances the oxidation of quercetin and kaempferol, whereas luteolin and rutin, each lacking the C-3 hydroxyl group, do not oxidize as readily, in the presence of $\mathrm{Cu}^{2+}$ ions.

Morin, which although it has a hydroxyl group at C-3 in the $\mathrm{C}$ ring, did not protect proteins against degradation. This is presumably due to the presence of a hydroxyl group at C-2' in the B ring of morin. In support of this, it has been reported that the addition of a hydroxyl group at C-2' lowers the phosphodiesterase (PDE) and $\mathrm{H}^{+}, \mathrm{K}^{+}$ATPase inhibitory activities of the flavonoids [36,43].

The antioxidant activity of flavonoids could also be dependent on their partitioning abilities between the aqueous and lipophilic environments [44,45]. The present study does suggest that the anti-protein-degradation activity would require the flavonoid to have partitioning ability towards lipophilic environment, as the flavonoids which showed anti-protein-degradation activity ranged from a very lipophilic such as 3-hydroxy flavone (insoluble in water) to quercetin which has an equal distribution between aqueous and lipophilic environments, whereas rutin which is more hydrophilic than quercetin (due to the presence of a disaccharide at C-3) did not prevent protein-degradation [33]. On the other hand, it seems unlikely for the anti-lipid-peroxidant activity to be dependent on the partitioning abilities of the flavonoids, as this activity was reported for various antioxidants ranging from a very water soluble compounds such as vitamin $\mathrm{C}$ to a very lipophilic compounds such as vita$\min \mathrm{E}[24,42]$.

Quercetin and 3,5,7-trihydroxy-4'-methoxy flavone-7rutinoside significantly protected erythrocytes against loss of erythrocyte deformability as compared with those treated with $\mathrm{H}_{2} \mathrm{O}_{2}$ alone (Table 2). In contrast, the flavonoids rutin, morin, chrysin, 2-carboxy ethyl dihydroxy flavone, $\alpha$-naphtho flavone and flavanone showed no effects on IF values (Table 2). The protective activity of the flavonoid 3,5,7-trihydroxy-4'-methoxy flavone-7rutinoside against loss of erythrocyte deformability appeared to be independent of lipid peroxidation since this flavonoid inhibited protein degradation in erythrocytes exposed to $\mathrm{H}_{2} \mathrm{O}_{2}$ without affecting lipid peroxidation (Table 2). Thus, these findings support our previous reports that under oxidative stress, the loss of deformability in erythrocytes or neutrophils is related to protein- degradation and independent of lipid peroxidation [12,24, 46].

Erythrocytes exposed to $\mathrm{H}_{2} \mathrm{O}_{2}$ exhibited increased sensitivity to osmotic shock when compared to controls. However, when these erythrocytes were pre-incubated with the flavonoids rutin and $\alpha$-naphtho flavone the osmotic fragility of $\mathrm{H}_{2} \mathrm{O}_{2}$-treated erythrocytes was not changed (Figure 1). On the contrary, pre-incubation of erythrocytes with the flavonoids quercetin and 3,5,7trihydroxy-4'-methoxy flavone-7-rutinoside decreased significantly the osmotic fragility of $\mathrm{H}_{2} \mathrm{O}_{2}$-treated erythrocytes (Figure 1), presumably because of their abilities 
to inhibit protein degradation. This would suggest that both quercetin and 3,5,7-trihydroxy-4'-methoxy flavone7-rutinoside make the cytoskeleton of erythrocytes more resistance to mechanical insult by protecting them against protein degradation. These findings also support our previous reports that under oxidative stress, the increase in osmotic fragility of the erythrocyte and the loss of erythrocyte deformability are related to protein-degradation rather than to lipid peroxidation $[12,24]$.

In conclusion, the flavonoids which had two hydroxyl groups in ring $\mathrm{B}$, regardless of their positions were found to be anti-lipid-peroxidant and the flavonoids which had an hydroxyl group at C-3 were found to be anti-protein-degradant as well as rheologically protecting against oxidant stress.

\section{ACKNOWLEDGEMENTS}

This study was funded by the Deanship of Academic Research of the University of Jordan.

\section{REFERENCES}

[1] Chiu, D., Kuypers, E. and Lubin, B. (1989) Lipid peroxidation in human red cells. Hematology, 26, 257-276.

[2] Davies, K.J.A. and Goldberg, A.L. (1987) Oxygen radicals stimulate intracellular proteolysis and lipid peroxidetion by independent mechanisms in erythrocytes. The Journal of Biological Chemistry, 262, 8220-8226.

[3] Saltman, P. (1989) Oxidative stress: A radical view. $\mathrm{He}-$ matology, 26, 249-256.

[4] Srour, M.A., Bilto, Y.Y. and Juma, M. (2000) Susceptibility of erythrocytes from non-insulin-dependent diabetes mellitus and hemodialysis patients, cigarette smokers and normal subjects to in vitro oxidative stress and loss of deformability. Microvascular Biology and Inflammation, 22, 173-180.

[5] Trotta, R.G., Sullivan, S.G. and Stern, A. (1981) Lipid peroxidation and hemoglobin degradation in red blood cells exposed to t-butyl hydroperoxide. Biochimica et Biophysica Acta, 679, 230-237. doi:10.1016/0304-4165(81)90211-7

[6] Snyder, L.M., Fortier, N.L., Trainor, J., Jacobs, J., Leb, L., Lubin, B., Chiu, D., Shohet, S. and Mohandas N. (1985) Effect of hydrogen peroxide exposure on normal human erythrocyte deformability, morphology, surface characteristics and spectrin-hemoglobin cross-linking. Journal of Clinical Investigation, 76, 1971-1977. doi:10.1172/JCI112196

[7] Chiu, D. and lubin, B. (1989) Oxidative hemoglobin denaturation and RBC destruction: The effect of heme on red cell membranes. Hematology, 26, 128-135.

[8] Van der zee, J., Steveninck, J.V., Koster, J.V., Koster, J.F. and Dubbel, Man, T.M. (1989) Inhibition of enzymes and oxidative damage of red blood cells induced by t-butyl hydroperoxide-derived radicals. Biochimica et Biophysica Acta, 980, 175-180.
[9] Pradhan, D., Weiser, M., Lumley-Sapanski, K., Frazier, D., Williamson, P. and Schlegel, R.A. (1990) Peroxidation induced perturbations of erythrocyte lipid organization. Biochimica et Biophysica Acta, 1023, 398-404. doi:10.1016/0005-2736(90)90132-8

[10] Van den Berg, J.J., Op den Kamp, J.A., Lubin, B.H., Roelofsen, B. and Kuypers, F.A. (1992) Kinetics and site specificity of hydroperoxide-induced oxidative damage in red blood cells. Free Radical Biology \& Medicine, 12, 487-498. doi:10.1016/0891-5849(92)90102-M

[11] Sato, Y., Kamo, S., Takahashi, T. and Suzuki, Y. (1995) Mechanism of free radical-induced hemolysis of human erythrocytes: Hemolysis by water-soluble radical initiator. Biochemistry, 34, 8940-8949. doi:10.1021/bi00028a002

[12] Srour, M.A., Bilto, Y.Y., Juma, M. and Irhimeh, M.R. (2000) Exposure of human erythrocytes to oxygen radicals causes loss of deformability, increased osmotic fragility, lipid peroxidation and protein degradation. Clinical Hemorheology and Microcircul, 23, 1-9.

[13] Halliwell, B. (1989) Protection against tissue damage in vivo by desferrioxamine: What is its mechanism of action? Free Radical Biology and Medicine, 7, 645-651. doi:10.1016/0891-5849(89)90145-7

[14] Miller, A.L. (1996). Antioxidant flavonoids: Structure, function and clinical usage. Alternative Medicine Review, 1, 103.

[15] Cao, G. Sofic, E.R. and Prior, R.L. (1996) Antioxidant capacity of tea and common vegetables. Journal of Agricultural and Food Chemistry, 44, 3426-3431. doi:10.1021/jf9602535

[16] Block, G. and Patterson, B. (1992) Fruits, vegetables and cancer prevention: A review of the epidemiological evidence. Nutrition and Cancer, 18, 1-29. doi:10.1080/01635589209514201

[17] Ness, A.R. and Powles, J.W. (1997) Fruit and vegetables and cardiovascular disease: A review. International Journal of Epidemiology, 26, 1-13. doi:10.1093/ije/26.1.1

[18] Cai, Y. Luo, Q. Sun, M. and Corke, H. (2004) Antioxidant activity and phenolic compounds of 112 traditional Chinese medicinal plants associated with anticancer. Life Science, 74, 2157-2184. doi:10.1016/j.lfs.2003.09.047

[19] Tawaha, F., Gharaibeh, M., Mohammad, M. and El-Elimate, T. (2007) Antioxidant activity and total phenolic content of selected Jordanian plant species. Food Chemistry, 104, 1372-1378. doi:10.1016/j.foodchem.2007.01.064

[20] Rice-Evans, C.A., Miller, N.J. and Paganga, G. (1996) Structure-antioxidant activity relationships of flavonoids and phenolic acids. Free Radical Biology and Medicine, 20, 933-956. doi:10.1016/0891-5849(95)02227-9

[21] Rice-Evans, C.A. Miller, N.J. and Paganga, G. (1997) Antioxidant properties of phenolic compounds. Trends in Food Science \& Technology, 2, 152-159.

[22] Harborne, J.B., (1967) Comparative biochemistry of flavonoids. Academic Press Inc., London.

[23] Hall, III, C.A. and Cuppett, S.L. (1997) Structure-activeties of natural antioxidants. In: Aruoma, O.I. and Cuppett, S.L., Eds., Antioxidant methodology: In vivo and in vitro 
concepts. AOCS Press, Illinois, 141-172.

[24] Suboh, S.M., Bilto, Y.Y. and Aburjai, T.A. (2004) Protective effects of selected medicinal plants against protein degradation, lipid peroxidation and deformability loss of oxidatively stressed human erythrocytes. Phytotherapy Research, 18, 280-284. doi:10.1002/ptr.1380

[25] Dacie, J.V. and Lewis, S.M. (1995) Practical haematology. 8th Edition, Churchil Livingstone, Edinburgh.

[26] Stocks, J. and Dormandy, T.L. (1971) The autoxidation of human red cell lipids induced by hydrogen peroxide. British Journal of Haematology, 20, 95-111. doi:10.1111/j.1365-2141.1971.tb00790.x

[27] Srour, M.A., Bilto, Y.Y. and Juma, M. (2000C) Evaluation of different methods used to measure malonyldialdehyde in human erythrocytes. Clinical Hemorheology and Microcircul, 23, 23-30.

[28] Davies, K.J.A. and Goldberg, A.L. (1987) Proteins damaged by oxygen radicals are rapidly degraded in extracts of red blood cells. The Journal of Biological Chemistry, 262, 8227-8234.

[29] Bilto, Y.Y., Player, M., West, M.J., Ellory, J.C. and Stuart, J. (1987) Effects of oxpentifylline on erythrocyte cation content, hydration and deformability. Clinical Hemorheology, 7, 561-577.

[30] Hanss M. (1983) Erythrocyte filterability measurement by the initial flow rate method. Biorheology, 20, 199-211.

[31] Bilto, Y.Y. and Stuart, J. (1985) Ultrasonic cleaning of polycarbonate membranes for measurement of erythrocyte filterability. Clinical Hemorheology, 5, 434-448.

[32] Luqman, S., Kaushik, S., et al. (2009) Protective effect of medicinal plant extracts on biomarkers of oxidative stress in erythrocytes. Pharmaceutical Biology (Formerly International Journal of Pharmacognosy), 47, 483-490. doi:10.1080/13880200902832900

[33] Brown, J.E., khodr, H., Hider, R.C. and Rice-Evans, C.A. (1998) Structural dependence of flavonoid interactions with $\mathrm{Cu}^{2+}$ ions: Implications for their antioxidant properties. Biochemical Journal, 330, 1173-1178.

[34] Choi, J.S., et al. (2002) The structure-Activity relationship of flavonoids as scavengers of peroxynitrite. Phytotherapy Research, 16, 232-235. doi:10.1002/ptr.828

[35] Ferrali, M., Signorini, C., Caciotti, B., Sugherini, L., Ciccoli, L., Giachetti, D. and Comporti, M. (1997) Protection against oxidative damage of erythrocyte membrane by the flavonoid quercetin and its relation to iron chelating activity. FEBS letters, 416, 123-129.

doi:10.1016/S0014-5793(97)01182-4
[36] Murakami, S., Muramatsu, M. and Tomisawa, K. (1999) Inhibition of gastric $\mathrm{H}^{+}, \mathrm{K}^{+}$-ATPase by flavonoids: A structure-activity study. Journal of Enzyme Inhibition, 14, 151-166. doi:10.3109/14756369909036551

[37] Pietta, P.G. (2000) Flavonoids as antioxidants. Journal of Natural Products, 63, 1036-1042. doi:10.1021/np9904509

[38] De Beer, D., Joubert, E., Gelderblom, W.C.A. and Manley, M. (2002) Phenolic compounds: A review of their possible role as in vivo antioxidants of wine. South African Journal for Enology and Viticulture, 23, 48-61.

[39] Perron, N.R. and Brumaghim, J.L. (2009) A review of the antioxidant mechanisms of polyphenol compounds related to iron binding. Cell Biochemistry and Biophysics, 53, 75-100. doi:10.1007/s12013-009-9043-X

[40] Rice-Evans, C. (2001) Flavonoid antioxidants. Current Medicinal Chemistry, 8, 797-807.

[41] Pathak, D., Pathak, K. and Singla, A.K. (1991) Flavanoids as medicinal agents-recent advances. Fitoterapia, 62, 371-389.

[42] Affany, A., Salvayre, R. and Douste-Blazy, L. (1987) Comparison of the protective effect of various flavonoids against lipid peroxidation of erythrocyte membranes (induced by cumene hydroperoxide). Fundamental \& Clinical Pharmacology, 1, 451-457. doi:10.1111/j.1472-8206.1987.tb00578.x

[43] Ruchstuhl, M. and Landry, Y. (1981) Inhibition of lung cyclic AMP- and cyclic GMP-phosphodiesterases by flavonoids and other chromone-like compounds. Biochemical Pharmacology, 30, 697-702. doi:10.1016/0006-2952(81)90153-2

[44] Foti, M., Piatelli, Baratta, M.T. and Ruberto, G. (1996) Flavonoids, coumarins, and cinnamic acids as antioxidants in a micellar system. Structure-activity relationship. Journal of Agricultural and Food Chemistry, 44, 497501. doi:10.1021/jf950378u

[45] Liao, K.-L. and Yin, M.-C. (2000) Individual and combined antioxidant effects of seven phenolic agents in human erythrocyte membrane ghosts and phosphatidylrcholine liposome systems: Importance of the partition coefficient. Journal of Agricultural and Food Chemistry, 48, 2266-2270. doi:10.1021/jf990946w

[46] Abu-Khader, A.A. and Bilto, Y.Y. (2002) Exposure of human neutrophils to oxygen radicals causes loss of deformability, lipid peroxidation, protein degradation, respiratory burst activation and loss of migration. Clinical Hemorheology and Microcircul, 27, 57-66. 